\title{
Clinical assessment of acute lateral ankle sprain injuries (ROAST): 2019 consensus statement and recommendations of the International Ankle Consortium
}

\author{
Eamonn Delahunt, ${ }_{1}^{1,2}$ Chris M Bleakley, ${ }^{3}$ Daniela S Bossard, ${ }^{1,2}$ Brian M Caulfield, ${ }^{1,4}$ \\ Carrie L Docherty, ${ }^{5}$ Cailbhe Doherty ${ }_{1}^{4}$ François Fourchet, ${ }^{6}$ Daniel T Fong, ${ }^{7}$ Jay Hertel, ${ }_{1}^{8}$ \\ Claire E Hiller, ${ }^{9}$ Thomas W Kaminski, ${ }^{10}$ Patrick O McKeon, ${ }^{11}$ Kathryn M Refshauge, ${ }^{9}$ \\ Alexandria Remus, ${ }^{4}$ Evert Verhagen, ${ }^{12}$ Bill T Vicenzino, ${ }^{13}$ Erik A Wikstrom, ${ }^{14}$ \\ Phillip A Gribble ${ }^{15}$
}

- Additional material is published online only. To view please visit the journal online (http://dx.doi.org/10.1136/ bjsports-2017-098885).

For numbered affiliations see end of article.

Correspondence to Dr Eamonn Delahunt, School of Public Health, Physiotherapy and Sports Science, University College Dublin, Dublin 4, Ireland;

eamonn.delahunt@ucd.ie

Accepted 4 May 2018 Published Online First 9 June 2018

\section{Linked}

http://dx.doi.org/10.1136/ bjsports-2017-098789

Check for updates

To cite: Delahunt $\mathrm{E}$ Bleakley CM, Bossard DS, et al. Br J Sports Med 2018:52:1304-1310.

\section{ABSTRACT}

Lateral ankle sprain injury is the most common musculoskeletal injury incurred by individuals who participate in sports and recreational physical activities. Following initial injury, a high proportion of individuals develop long-term injury-associated symptoms and chronic ankle instability. The development of chronic ankle instability is consequent on the interaction of mechanical and sensorimotor insufficiencies/impairments that manifest following acute lateral ankle sprain injury. To reduce the propensity for developing chronic ankle instability, clinical assessments should evaluate whether patients in the acute phase following lateral ankle sprain injury exhibit any mechanical and/or sensorimotor impairments. This modified Delphi study was undertaken under the auspices of the executive committee of the International Ankle Consortium. The primary aim was to develop recommendations, based on expert $(n=14)$ consensus, for structured clinical assessment of acute lateral ankle sprain injuries. After two modified Delphi rounds, consensus was achieved on the clinical assessment of acute lateral ankle sprain injuries. Consensus was reached on a minimum standard clinical diagnostic assessment. Key components of this clinical diagnostic assessment include: establishing the mechanism of injury, as well as the assessment of ankle joint bones and ligaments. Through consensus, the expert panel also developed the International Ankle Consortium Rehabilitation-Oriented ASsessmenT (ROAST). The International Ankle Consortium ROAST will help clinicians identify mechanical and/or sensorimotor impairments that are associated with chronic ankle instability. This consensus statement from the International Ankle Consortium aims to be a key resource for clinicians who regularly assess individuals with acute lateral ankle sprain injuries.

\section{INTRODUCTION}

Lateral ankle sprains are the most common lower limb musculoskeletal injury incurred by individuals who participate in sports and recreational physical activities. ${ }^{12}$ The prevalence of lateral ankle sprains among the general population is also substantial, as demonstrated by hospital emergency department data. $^{3-6} \mathrm{Up}$ to $70 \%$ of the general population report having incurred an ankle injury during their lifetime. ${ }^{7}$

Lateral ankle sprain injuries associate with high societal economic costs, related to injury diagnosis, initial management, rehabilitation and reduced work productivity. In the UK, Cooke et $a l^{6}$ reported an average of 6.9 days of paid work lost due to lateral ankle sprain injuries, adding at least an additional $£ 805$ in lost productivity costs for each injury to the overall costs, compared with $£ 135$ of direct healthcare costs. The combination of high incidence and both direct and indirect costs makes the economic burden of lateral ankle sprain injuries indisputable.

Lateral ankle sprain injuries have the highest reinjury rate of all lower limb musculoskeletal injuries. ${ }^{8}$ Individuals who incur an acute lateral ankle sprain injury have a twofold increased risk of reinjury in the year following their initial injury. ${ }^{9}$ Reinjury coincides with the progression of a number of chronic injury-associated sequelae including: pain, persistent swelling, feelings of ankle joint instability, ankle joint 'giving-way', recurrent injury and reduced functional capacity as illustrated by reduced scores on patient-reported outcome measures questionnaires. ${ }^{1} 2$ 10-12 These injury-associated sequelae constitute the characteristic features of chronic ankle instability. ${ }^{10-13}$ High reinjury rates might be due to inadequate rehabilitation, ${ }^{12}$ and/or premature return to sport. ${ }^{14}$ Hence, reducing the risk of reinjury and the propensity for the development of chronic ankle instability is a key priority after acute lateral ankle sprain injury occurrence. ${ }^{15}$

The interaction of mechanical and sensorimotor impairments that manifest following acute lateral ankle sprain injury contribute to the development of chronic ankle instability. ${ }^{16}$ Therefore, clinical assessments should evaluate whether a patient in the acute phase following lateral ankle sprain injury exhibits any mechanical and/or sensorimotor impairments. However, previous research has documented that clinicians may have a limited understanding of the full spectrum of mechanical and sensorimotor impairments that manifest following an acute lateral ankle sprain injury. ${ }^{17}$ Hence, the 
treatment being administered following acute lateral ankle sprain injury is unlikely to be based on objectively identified mechanical and sensorimotor impairments. As such, it is necessary to develop recommendations for structured clinical assessment following acute lateral ankle sprain injury, which addresses both mechanical and sensorimotor impairments. Considering this, the aim of this project was to develop, based on expert consensus, recommendations for structured clinical assessment of acute lateral ankle sprain injuries. These recommendations should have a particular emphasis on impairments that are known to associate with chronic ankle instability.

\section{MATERIALS AND METHODS Study design}

This modified (consisting of two rounds) Delphi study was undertaken under the auspices of the executive committee of the International Ankle Consortium. The International Ankle Consortium, which was inaugurated in 2004, is an international community of researchers and clinicians whose primary academic purpose is to promote scholarship and dissemination of research-informed knowledge related to ankle sprain injury and chronic ankle instability. A previous consensus statement of the International Ankle Consortium ${ }^{2}$ and its supporting evidence document ${ }^{1}$ were used as the starting point for this modified Delphi study. The protocol for the present modified Delphi study, which details the study methodology, has been published. ${ }^{18}$ In summary, our modified Delphi process started with an anonymous online questionnaire (round 1) specifically related to the clinical assessment of acute lateral ankle sprain injuries. The online questionnaire consisted of a number of distinct sections including: (1) participant demographics; (2) subjective assessment and patient-reported outcome measures; (3) diagnostic imaging; (4) objective assessment (including asssessment of bony integrity, ligamentous integrity, range of motion, arthrokinematics, strength, neurodynamics and postural balance); and (5) performance assessment. An email was sent to all members of the executive committee of the International Ankle Consortium requesting their participation in the online questionnaire. Participants were required to complete the online questionnaire within 4 weeks of receiving the invitation email. A reminder email was sent to all participants 2 weeks after the initial invitation email. Regarding the online questionnaire, participants were requested to respond to questions related to the importance of different constructs of the clinical assessment of acute lateral ankle sprain injuries on a scale of $1-5 \quad(1=$ strongly disagree; $2=$ disagree; $3=$ no opinion; $4=$ agree; and $5=$ strongly agree). They also had the opportunity to elaborate further on how they would assess certain structures or functions by providing expanded answers to open-ended questions. The responses to the online questionnaire were collated, analysed (completed August 2017) and used as the foundation for a subsequent consensus meeting of the executive committee of the International Ankle Consortium (ie, international multidisciplinary expert group). This consensus meeting (held on 14 September 2017) represented round 2 of this modified Delphi method.

\section{Data analysis}

Data from round 1 were automatically extracted from the online questionnaire to a Google Sheets document. For questions with a Likert scale response, frequency tables were automatically generated, and the level of agreement was calculated for each response. To establish the level of agreement, the total percentage of 'strongly agree' (5 on the Likert scale) and 'agree' (4 on the
Likert scale) responses was calculated. Consensus agreement was defined as $\geq 75 \%$, partial agreement was defined as 50\%-75\% agreement, while no agreement was defined as $<50 \%$. Qualitative data (ie, open-ended responses to questions as part of the online questionnaire) and responses that reached partial agreement were used as discussion points in round 2 of the modified Delphi process.

\section{RESULTS}

After two consecutive modified Delphi rounds, performed between May 2017 and September 2017, full consensus was achieved on the clinical assessment of acute lateral ankle sprain injuries (figure 1 and table 1).

\section{Expert panel}

Fourteen experts from the executive committee of the International Ankle Consortium were invited to participate, all of who agreed. The expert panel (males $=84.6 \%$, females $=15.4 \%$; age $=45 \pm 6.2$ years) were employed in a number of countries including Australia, Ireland, the Netherlands, Switzerland, USA and the UK. All expert panel members had authored or coauthored numerous peer-reviewed articles on the topics of lateral ankle sprain and chronic ankle instability, as well as having contributed to previous consensus statements. The years of clinical experience varied $(15.7 \pm 13.5$ years) across the members. The expert panel members assessed an average of 40 patients a year with lateral ankle sprain injuries and/or chronic ankle instability. The expert panel members identified their expertise in the clinical assessment of patients with acute lateral ankle sprain injuries and/or chronic ankle instability as an average of 8 out of 10 , with 10 being the highest level of expertise.

\section{Delphi round 1}

All experts (100\%) participated in round 1; however, answers for one participant were excluded due to technical issues. Thirteen participants successfully completed round 1. Expert consensus ( $\geq 75 \%$ agreement) was reached on 37 of the 62 questions included in the online questionnaire. Fifteen criteria reached partial agreement (50\%-75\%) and hence were brought forward for discussion in round 2. Online supplementary file table 1 details the level of agreement for each of the questions in the online questionnaire.

\section{Delphi round 2}

Ten of the 14 expert panel members were able to attend the executive committee meeting of the International Ankle Consortium, which functioned as round 2 of the modified Delphi process. This meeting took place the day before the 7 th International Ankle Symposium (14 September 2017). Results from round 1, which reached $\geq 75 \%$ agreement, were automatically included in this consensus. Results from round 1 that reached partial agreement $(50 \%-75 \%)$ along with responses to open-ended questions (part of the online questionnaire) were discussed further among the 10 experts who were present at round 2. To establish the level of agreement in round 2, the total percentage of 'strongly agree' (5 on the Likert scale) and 'agree' (4 on the Likert scale) responses was calculated. Consensus agreement was defined as $\geq 75 \%$. Final consensus was reached in round 2 and is presented in figure 1 and table 1 .

\section{DISCUSSION}

This modified Delphi study involving experts from the executive committee of the International Ankle Consortium reached 


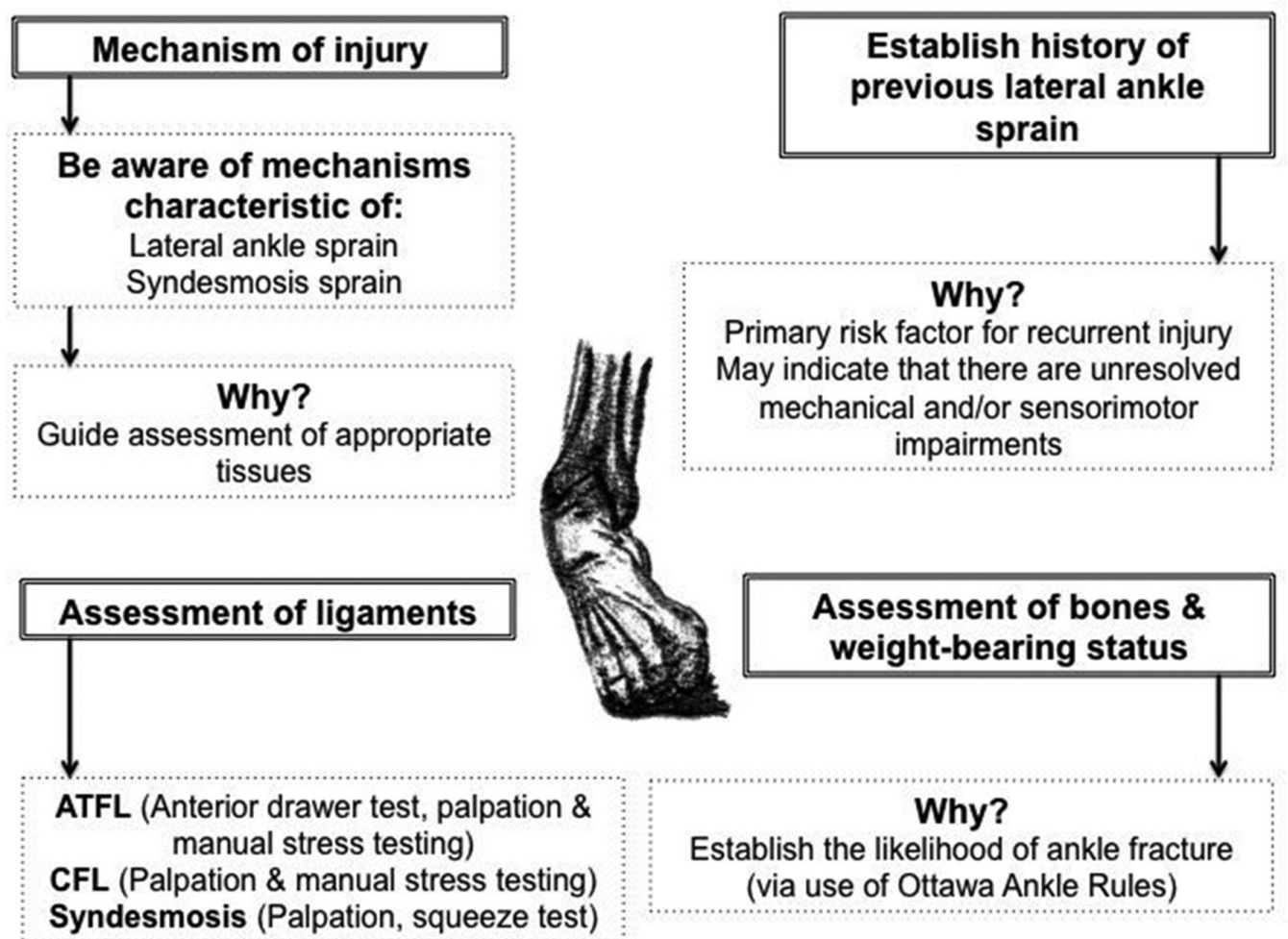

Figure 1 Clinical diagnostic assessment. ATFL, anterior talofibular ligament; CFL, calcaneofibular ligament.

consensus on recommendations for clinical assessment of acute lateral ankle sprain injuries. With regard to injury diagnosis, there were five important considerations, which the expert panel reached consensus on. These are as follows: (1) mechanism of injury; (2) history of previous lateral ankle sprain; (3) weightbearing status; (4) clinical assessment of bones; and (5) clinical assessment of ligaments. Hence, the experts agreed that these should be clustered into a clinical diagnostic assessment.

Regarding the evaluation of mechanical and sensorimotor impairments, there were 10 important considerations, which the expert panel reached consensus on. These are as follows: (1) pain; (2) swelling; (3) range of motion; (4) arthrokinematics; (5)

Table 1 International Ankle Consortium ROAST

\begin{tabular}{|c|c|c|}
\hline $\begin{array}{l}\text { What clinicians should assess following } \\
\text { acute lateral ankle sprain injury }\end{array}$ & Why? & How? \\
\hline Ankle joint pain & $\begin{array}{l}\text { Guide progression of exercise-based rehabilitation. } \\
\text { Assess the efficacy of treatments implemented. }\end{array}$ & $\begin{array}{l}\text { Numeric rating scale for pain. }{ }^{35} \\
\text { FADI. }^{36}\end{array}$ \\
\hline Ankle joint swelling & $\begin{array}{l}\text { Swelling can cause arthrogenic muscle inhibition. } \\
\text { Guide progression of exercise-based rehabilitation. } \\
\text { Evaluate the efficacy of treatments implemented. }\end{array}$ & Figure-of-eight. $^{38-41}$ \\
\hline Ankle joint range of motion & $\begin{array}{l}\text { High propensity for the development of a dorsiflexion deficit. } \\
\text { Impairments in ankle joint range of motion are consistently identified in individuals } \\
\text { with CAI. }\end{array}$ & Weight-bearing lunge test. ${ }^{44-46}$ \\
\hline Ankle joint arthrokinematics & $\begin{array}{l}\text { Disruption in ankle joint arthrokinematics can result in a dorsiflexion deficit. } \\
\text { Impairments in ankle joint arthrokinematics are regularly identified in individuals with } \\
\text { CAl. }\end{array}$ & Posterior talar glide test. ${ }^{48}$ \\
\hline Ankle joint muscle strength & $\begin{array}{l}\text { Impairments in ankle joint strength compromise the functional integrity of the ankle } \\
\text { joint. } \\
\text { Impairments in ankle joint strength are regularly identified in individuals with CAI. }\end{array}$ & Hand-held dynamometry. ${ }^{53}$ \\
\hline Static postural balance & $\begin{array}{l}\text { Impairments in static postural balance are consistently identified in individuals with } \\
\text { CAI. }\end{array}$ & $\begin{array}{l}\text { BESS. }^{56} \\
\text { FLT. }^{57}\end{array}$ \\
\hline Dynamic postural balance & $\begin{array}{l}\text { Impairments in dynamic postural balance are consistently identified in individuals with } \\
\text { CAl. }\end{array}$ & SEBT $^{58}$ \\
\hline Gait & Impairments in gait are consistently identified in individuals with CAI. & Visual assessment for antalgic gait. \\
\hline Physical activity level & Guide the specificity of exercise-based rehabilitation. & Tegner activity-level scale. ${ }^{63}$ \\
\hline $\begin{array}{l}\text { Ankle joint specific patient-reported } \\
\text { outcome measures }\end{array}$ & Evaluate the efficacy of treatments implemented. & $\begin{array}{l}\text { FADI. }^{36} \\
\text { FAAM. }^{65}\end{array}$ \\
\hline
\end{tabular}

BESS, Balance Error Scoring System; CAI, chronic ankle instability; FAAM, Foot and Ankle Ability Measure; FADI, Foot and Ankle Disability Index; FLT, Foot Lift Test; ROAST, Rehabilitation-Oriented AS-sessmenT; SEBT, Star Excursion Balance Test. 
muscle strength; (6) static postural balance; (7) dynamic postural balance; (8) gait; (9) physical activity level; and (10) patient-reported outcome measures. Hence, the experts agreed that these should be clustered and termed the International Ankle Consortium Rehabilitation-Oriented ASsessmenT (ROAST). We advocate that clinicians should consult these recommendations as they detail an imperative first step towards the development of an appropriate management pathway for this prevalent injury.

\section{Clinical diagnostic assessment}

The expert panel agreed on a pragmatic minimum standard clinical diagnostic assessment, which does not require specialist equipment (eg, diagnostic imaging) and can be applied across a range of clinical settings.

\section{Mechanism of injury}

Establishing the mechanism of injury is advocated as it can give clinicians an indication of what anatomical structures are likely to have incurred insult, and hence what tissues should be prioritised during clinical assessment. Numerous published articles have described the kinematics of lateral ankle sprain injury occurrences. ${ }^{19-24}$ Clinicians should suspect injury to the lateral ligaments of the ankle joint if the patient reports that the mechanism of injury involved a sudden rapid inversion and internal rotation loading of the foot and ankle complex, irrespective of sagittal plane angular displacement. The mechanisms of injury associated with ankle syndesmosis ligament injuries are less clear but have been reported to include external rotation of the foot, eversion of the talus within the ankle mortise and excessive dorsiflexion. ${ }^{25}$ Therefore, clinicians should suspect injury to the syndesmosis ligaments if the patient describes/recalls any of the aforementioned injury mechanisms (ie, external rotation of the foot and hyperdorsiflexion).

\section{History of previous lateral ankle sprain}

Establishing history of previous lateral ankle sprain injury or ankle joint injury is endorsed primarily for two reasons. First, it has been established that previous lateral ankle sprain injury heightens the risk of injury recurrence. ${ }^{26}{ }^{27}$ Second, if the presenting patient has previously sustained a lateral ankle sprain injury, it is probable that injury-associated mechanical and sensorimotor impairments are present, which should be addressed as part of a comprehensive rehabilitation programme.

\section{Weight-bearing status}

Weight-bearing status should be established, both via subjective reporting related to the time of injury and during clinical presentation in accordance with the Ottawa Ankle Rules. An inability to weight-bear four steps immediately after injury and on clinical presentation should alert clinicians to the possibility of ankle joint fracture. ${ }^{28}$ The likelihood of ankle joint fracture can be established with high sensitivity by using the Ottawa Ankle Rules, whereby weight-bearing status and clinical assessment of the 'malleolar zone' are combined in a clinical prediction rule. ${ }^{28}$

\section{Clinical assessment of bones}

The Ottawa Ankle Rules ${ }^{28}$ should be used to determine the likelihood of ankle joint fracture. If a patient reports pain in the 'malleolar zone' and if this is accompanied by pain on palpation of the distal $6 \mathrm{~cm}$ of the posterior edge of the medial malleolus, or pain on palpation of the distal $6 \mathrm{~cm}$ of the posterior edge of the lateral malleolus, or an inability to weight-bear four steps immediately after injury and on clinical presentation, then an ankle joint X-ray is warranted (online supplementary appendix I). The Ottawa Ankle Rules have been reported to have higher sensitivity than specificity, meaning that they are better at ruling out the possibility of ankle joint fracture, rather than making a diagnosis of ankle joint fracture. ${ }^{29}$ Following an inversion and internal rotation injury of the ankle joint, the pretest probability of ankle joint fracture is less than $15 \% .^{30}$ If the Ottawa Ankle Rules are implemented in such instances but findings are negative (ie, none of the rules are positive; negative likelihood ratio $=0.02$ ), the post-test probability of ankle joint fracture is less than $1 \%$.

\section{Clinical assessment of ligaments}

The clinical assessment of the integrity of the lateral ligaments of the ankle joint, as well as the ankle joint syndesmosis ligaments is advocated. The main lateral ligamentous stabilisers of the ankle joint are: the anterior talofibular ligament, the calcaneofibular ligament and the posterior talofibular ligament. The anterior talofibular ligament is the most commonly injured of these ligaments. ${ }^{31}$ It originates at the anterior margin of the lateral malleolus, and it runs anteromedially to insert on the talar body immediately anterior to the joint surface occupied by the lateral malleolus. ${ }^{32}$ Replication of the patient's 'known pain' on palpation and/or stressing (ie, passive plantar flexion and inversion) of the anterior talofibular ligament is indicative of injury to this ligament (online supplementary appendix I). Clinical stability tests to assess for complete disruption of the anterior talofibular ligament are best performed between 4 days and 6 days after injury. ${ }^{33}$ The anterior drawer test is the most sensitive clinical stability test to assess for complete rupture of the anterior talofibular ligament. ${ }^{33}$ The sensitivity and specificity of this test are 0.96 and 0.84 , respectively, with an associated negative likelihood ratio of $0.04 .^{33}$ This means that if there is no 'sulcus sign' on testing the integrity of the anterior talofibular ligament using the anterior drawer test, then there is low probability that it is completely disrupted/ruptured (online supplementary appendix I).

The calcaneofibular ligament originates from the anterior part of the lateral malleolus and courses obliquely downwards and backwards to attach to the posterior region of the lateral calcaneal surface. ${ }^{32}$ It is superficially crossed by the peroneal tendons and sheaths, with only approximately $1 \mathrm{~cm}$ of the ligament being uncovered and directly palpable. Replication of the patient's 'known pain' on palpation and/or stressing (ie, passive dorsiflexion of the ankle joint combined with passive inversion of the rearfoot) of the calcaneofibular ligament is indicative of injury to this ligament (online supplementary appendix I).

The prevalence of ankle joint syndesmosis ligament injury (with or without concomitant lateral ligament involvement) has been reported to be $20 \%{ }^{31}$ As such, it is important to undertake a clinical assessment of the ankle joint syndesmosis ligaments. Sman and colleagues $^{34}$ have reported that localised tenderness on palpation of the syndesmosis ligaments is the most sensitive clinical assessment test (sensitivity=0.92), while the squeeze test is the most specific clinical assessment test (specificity $=0.88$ ). Thus, if the most sensitive clinical assessment test (palpation of the syndesmosis ligaments) and the most specific clinical assessment test (squeeze test) are positive, there is a high probability of injury to the syndesmosis ligaments (online supplementary appendix I).

\section{International Ankle Consortium ROAST}

The expert panel agreed on a rehabilitation-oriented assessment, with the primary purpose of identifying the presence of mechanical and/or sensorimotor impairments that are known to contribute to the development of chronic ankle instability. To 
determine the true presence of these impairments in the acute phase following injury clinicians can potentially use the non-injured side as a comparator.

\section{Pain}

Quantification of a patient's current self-reported ankle joint pain is endorsed. Self-reported pain should be used as a clinically oriented outcome measure to guide the progression of exercise-based rehabilitation and to assess the efficacy of treatments implemented. Numerous options exist for assessing ankle joint pain in clinical settings. The numeric rating scale for pain is a valid and reliable scale to measure pain intensity. ${ }^{35}$ It can be administered both verbally and in writing and can be used to quantify pain during various activities. However, it only evaluates one component of the pain experience, namely, pain intensity. The assessment of ankle-specific pain is a central component of the Foot and Ankle Disability Index, which is a patient-reported outcome questionnaire designed to assess functional limitations related to foot and ankle conditions. ${ }^{36}$

\section{Swelling}

The assessment of ankle joint swelling is advocated. Ankle joint swelling may alter somatosensory input to the central nervous system which, through the process of arthrogenic muscle inhibition, could negatively affect functional joint stability. ${ }^{37}$ The quantification of ankle joint swelling should be used as a clinically oriented outcome measure to direct exercise-based rehabilitation progression and to measure the efficacy of therapeutic interventions. The figure-of-eight method has been reported to be a valid and reliable clinically applicable method for indirectly quantifying ankle joint swelling (online supplementary appendix I). ${ }^{38-41}$

\section{Range of motion}

A comprehensive assessment of both passive and active ankle joint range of motion is endorsed. The quantification of ankle joint range of motion should be used as a clinically oriented outcome measure to guide exercise-based rehabilitation progression and to gauge the efficacy of therapeutic interventions. Of particular concern following lateral ankle sprain injury is the propensity for the development of a restriction in ankle joint dorsiflexion range of motion. ${ }^{42}$ Sufficient ankle joint dorsiflexion range of motion is important as it has been reported to explain up to $28 \%$ of the variance in dynamic postural balance performance, as assessed via the anterior reach direction of the Star Excursion Balance Test. ${ }^{43}$ The weight-bearing lunge test is a clinically applicable, valid and reliable method for assessing ankle joint dorsiflexion range of motion (online supplementary appendix I). ${ }^{44-46}$

\section{Arthrokinematics}

Assessment of talocrural joint arthrokinematics is advocated. It has been proposed that impairments in ankle joint dorsiflexion range of motion are likely related to a disruption in talocrural arthrokinematics. ${ }^{16}$ This is supported by studies that have reported either restrictions in posterior talar glide, ${ }^{48}$ or the existence of an anterior positional fault of the talus within the talocrural joint. ${ }^{4950}$ The posterior talar glide test as reported by Denegar $e{ } a l^{48}$ can be used to assess posterior glide of the talus within the talocrural joint.

\section{Muscle strength}

Assessment of ankle joint muscle strength is advocated. During the contractile process, musculotendinous units generate stiffness, resulting in dynamic protection of joints. A strength deficit of the ankle musculature could compromise the integrity of the ankle joint to withstand sudden injurious movements. Individuals with chronic ankle instability have been reported to exhibit deficits in ankle joint strength. ${ }^{51}$ Muscle strength can be measured objectively using isokinetic dynamometers and handheld dynamometers. A hand-held dynamometer offers a practical, clinically applicable alternative to isokinetic dynamometry due to its portability, reduced cost and convenient size. ${ }^{52}$ Ankle joint strength can be measured in an objective and reliable manner using hand-held dynamometry (online supplementary appendix I). ${ }^{53}$ Additionally, there is evidence to suggest that hip strength may be an important factor to also consider, as research has identified proximal strength deficits in individuals with chronic ankle instability. ${ }^{54}$

\section{Static postural balance}

Assessing static postural balance is endorsed as an integral component of a rehabilitation-oriented clinical assessment following acute lateral ankle sprain injury. Deficiencies in static postural balance have been consistently identified in individuals with chronic ankle instability. ${ }^{55}$ Both the Balance Error Scoring System $^{56}$ and the Foot Lift Test ${ }^{57}$ are clinically applicable methods for assessing static postural balance performance (online supplementary appendix I).

\section{Dynamic postural balance}

Assessing dynamic postural balance is endorsed as a central component of a rehabilitation-oriented clinical assessment following acute lateral ankle sprain injury. Impairments in dynamic postural balance performance have been steadfastly identified in individuals with chronic ankle instability. ${ }^{58}$ The Star Excursion Balance Test can be readily used in the clinic to assess dynamic postural balance performance (online supplementary appendix I). ${ }^{58}$

\section{Gait}

Assessment of walking gait is endorsed following acute lateral ankle sprain injury. It has been posited that the high potential for lateral ankle sprain injury recurrence during gait is likely due to inappropriate positioning of the lower extremity joints in the loading-unloading transitions between stance and swing. ${ }^{59} 60$ Aberrancies in lower extremity biomechanics during walking gait have been consistently identified in individuals with chronic ankle instability. ${ }^{61} 62$

\section{Physical activity level}

Establishing the patient's level of physical activity prior to incurring their lateral ankle sprain injury is endorsed primarily for two reasons. First, it can help guide the specificity of exercise-based rehabilitation. Second, it can be used to establish whether the patient has returned to his or her preinjury participation level. An example of an appropriate questionnaire is the Tegner activity-level scale (online supplementary appendix I). ${ }^{63}$

\section{Patient-reported outcome measures}

Patient-reported outcome measures improve the quality of assessing, and reporting the outcome of treatments and their use as part of a rehabilitation-oriented clinical assessment following lateral ankle sprain injury is advocated. A number of patient-reported outcome measures exist, which have been commonly used with individuals with chronic ankle instability. ${ }^{64}$ Examples of appropriate patient-reported outcome measures to assess function of the ankle include the Foot and Ankle Disability Index ${ }^{36}$ 
and the Foot and Ankle Ability Measure (online supplementary appendix I). ${ }^{65}$

\section{Future research}

High-quality prospective research is needed to determine whether these recommendations for clinical assessment of acute lateral ankle sprain injuries can optimise the management of individuals who have incurred this injury.

\section{CONCLUSION}

The executive committee of the International Ankle Consortium reached consensus on recommendations for structured clinical assessment of acute lateral ankle sprain injuries. Recommendations are provided on an initial diagnostic clinical assessment. The International Ankle Consortium ROAST is also presented, which places emphasis on the assessment of mechanical and sensorimotor impairments that are known to associate with chronic ankle instability.

\section{Author affiliations}

${ }^{1}$ School of Public Health, Physiotherapy and Sports Science, University College Dublin, Dublin, Ireland

${ }^{2}$ Institute for Sport and Health, University College Dublin, Dublin, Ireland ${ }^{3}$ Department of Physical Therapy, High Point University, High Point, North Carolina, USA

${ }^{4}$ Insight Centre for Data Analytics, University College Dublin, Dublin, Ireland

${ }^{5}$ School of Public Health, Indiana University, Bloomington, Indiana, USA

${ }^{6}$ Motion Analysis Laboratory, Hôpital De La Tour, Geneva, Switzerland

${ }^{7}$ School of Sport, Exercise and Health Sciences, National Centre for Sport and

Exercise Medicine, Loughborough University, Loughborough, UK

${ }^{8}$ Department of Kinesiology, Curry School of Education, University of Virginia,

Charlottesville, Virginia, USA

${ }^{9}$ School of Physiotherapy, Faculty of Health Sciences, University of Sydney, Sydney, New South Wales, Australia

${ }^{10}$ Department of Kinesiology and Applied Physiology, University of Delaware, Newark, Delaware, USA

${ }^{11}$ School of Health Sciences and Human Performance, Ithaca College, Ithaca, New York, USA

${ }^{12}$ Amsterdam Collaboration on Health and Safety in Sports and Department of Public and Occupational Health, Amsterdam Movement Science, VU University Medical Center, Amsterdam, The Netherlands

${ }^{13}$ School of Health and Rehabilitation Sciences, University of Queensland, Brisbane, Queensland, Australia

${ }^{14}$ Department of Exercise and Sport Science, University of North Carolina at Chapel Hill, Chapel Hill, North Carolina, USA

${ }^{15}$ Division of Athletic Training, College of Health Sciences, University of Kentucky, Lexington, Kentucky, USA

Contributors All authors have made substantial contributions to this manuscript. They have all participated in the concept and design, analysis and interpretation of data and drafting and revising the manuscript. All authors have read the manuscript and agreed to submission for publication.

Funding The authors have not declared a specific grant for this research from any funding agency in the public, commercial or not-for-profit sectors.

Competing interests None declared.

Patient consent Not required.

Ethics approval University College Dublin Human Research Ethics Committee.

Provenance and peer review Not commissioned; externally peer reviewed.

(c) Article author(s) (or their employer(s) unless otherwise stated in the text of the article) 2018. All rights reserved. No commercial use is permitted unless otherwise expressly granted.

\section{REFERENCES}

1 Gribble PA, Bleakley CM, Caulfield BM, et al. Evidence review for the 2016 International Ankle Consortium consensus statement on the prevalence, impact and long-term consequences of lateral ankle sprains. Br J Sports Med 2016;50:1496-505

2 Gribble PA, Bleakley CM, Caulfield BM, et al. 2016 consensus statement of the International Ankle Consortium: prevalence, impact and long-term consequences of lateral ankle sprains. Br J Sports Med 2016;50:1493-5.
3 Feger MA, Glaviano NR, Donovan L, et al. Current trends in the management of lateral ankle sprain in the United States. Clin J Sport Med 2017:27:145-52.

4 Shah S, Thomas AC, Noone JM, et al. Incidence and cost of ankle sprains in United States Emergency Departments. Sports Health 2016:8:547-52.

5 Waterman BR, Owens BD, Davey $\mathrm{S}$, et al. The epidemiology of ankle sprains in the United States. J Bone Joint Surg Am 2010;92:2279-84.

6 Cooke MW, Lamb SE, Marsh J, et al. A survey of current consultant practice of treatment of severe ankle sprains in emergency departments in the United Kingdom. Emerg Med J 2003;20:505-7.

7 Hiller CE, Nightingale EJ, Raymond J, et al. Prevalence and impact of chronic musculoskeletal ankle disorders in the community. Arch Phys Med Rehabil 2012;93:1801-7.

8 Anandacoomarasamy A, Barnsley L. Long term outcomes of inversion ankle injuries. Br J Sports Med 2005;39:e14.

9 Verhagen EA, van Tulder M, van $\operatorname{der} B e e k A J$, et al. An economic evaluation of a proprioceptive balance board training programme for the prevention of ankle sprains in volleyball. Br J Sports Med 2005:39:111-5.

10 Gribble PA, Delahunt E, Bleakley C, et al. Selection criteria for patients with chronic ankle instability in controlled research: a position statement of the International Ankle Consortium. Br J Sports Med 2014;48:1014-8.

11 Gribble PA, Delahunt E, Bleakley CM, et al. Selection criteria for patients with chronic ankle instability in controlled research: a position statement of the International Ankle Consortium. J Ath/ Train 2014;49:121-7.

12 Gribble PA, Delahunt E, Bleakley C, et al. Selection criteria for patients with chronic ankle instability in controlled research: a position statement of the International Ankle Consortium. J Orthop Sports Phys Ther 2013:43:585-91.

13 Delahunt E, Coughlan GF, Caulfield B, et al. Inclusion criteria when investigating insufficiencies in chronic ankle instability. Med Sci Sports Exerc 2010:42:2106-21.

14 Medina McKeon JM, Bush HM, Reed A, et al. Return-to-play probabilities following new versus recurrent ankle sprains in high school athletes. J Sci Med Sport 2014;17:23-8.

15 Kaminski TW, Hertel J, Amendola N, et al. National Athletic Trainers' Association position statement: conservative management and prevention of ankle sprains in athletes. J Athl Train 2013;48:528-45.

16 Hertel J. Functional anatomy, pathomechanics, and pathophysiology of lateral ankle instability. J Ath/ Train 2002;37:364-75.

17 Kerin F, Delahunt E. Physiotherapists' Understanding of Functional and Mechanical Insufficiencies Contributing to Chronic Ankle Instability. Athletic Training \& Sports Health Care 2011:3:125-30.

18 Bossard DS, Remus A, Doherty C, et al. Developing consensus on clinical assessment of acute lateral ankle sprain injuries: protocol for an international and multidisciplinary modified Delphi process. Br J Sports Med 2018. doi: 10.1136 bjsports-2017-099007. [Epub ahead of print].

19 Skazalski C, Kruczynski J, Bahr MA, et al. Landing-related ankle injuries do not occur in plantarflexion as once thought: a systematic video analysis of ankle injuries in world-class volleyball. Br J Sports Med 2018:52:74-82.

20 Terada M, Gribble PA. Jump Landing Biomechanics During a Laboratory Recorded Recurrent Ankle Sprain. Foot Ankle Int 2015:36:842-8.

21 Gehring D, Wissler S, Mornieux G, et al. How to sprain your ankle - a biomechanical case report of an inversion trauma. J Biomech 2013:46:175-8.

22 Fong DT, Ha SC, Mok KM, et al. Kinematics analysis of ankle inversion ligamentous sprain injuries in sports: five cases from televised tennis competitions. Am J Sports Med 2012:40:2627-32

23 Mok KM, Fong DT, Krosshaug T, et al. Kinematics analysis of ankle inversion ligamentous sprain injuries in sports: 2 cases during the 2008 Beijing Olympics. Am J Sports Med 2011;39:1548-52.

24 Fong DT, Hong Y, Shima Y, et al. Biomechanics of supination ankle sprain: a case report of an accidental injury event in the laboratory. Am J Sports Med 2009:37:822-7.

25 Lin CF, Gross ML, Weinhold P. Ankle syndesmosis injuries: anatomy, biomechanics, mechanism of injury, and clinical guidelines for diagnosis and intervention. J Orthop Sports Phys Ther 2006;36:372-84.

26 Kucera KL, Marshall SW, Wolf SH, et al. Association of injury history and incident injury in cadet basic military training. Med Sci Sports Exerc 2016:48:1053-61.

27 Tyler TF, McHugh MP, Mirabella MR, et al. Risk factors for noncontact ankle sprains in high school football players: the role of previous ankle sprains and body mass index. Am J Sports Med 2006;34:471-5.

28 Stiell IG, Greenberg GH, McKnight RD, et al. Decision rules for the use of radiography in acute ankle injuries. Refinement and prospective validation. JAMA 1993:269:1127-32.

29 Beckenkamp PR, Lin CC, Macaskill P, et al. Diagnostic accuracy of the Ottawa Ankle and Midfoot Rules: a systematic review with meta-analysis. Br J Sports Med 2017:51:504-10.

30 Bachmann LM, Kolb E, Koller MT, et al. Accuracy of Ottawa ankle rules to exclude fractures of the ankle and mid-foot: systematic review. BMJ 2003;326:417.

31 Roemer FW, Jomaah N, Niu J, et al. Ligamentous injuries and the risk of associated tissue damage in acute ankle sprains in athletes: a cross-sectional MRI study. Am J Sports Med 2014;42:1549-57. 
32 Golanó P, Vega J, de Leeuw PA, et al. Anatomy of the ankle ligaments: a pictorial essay. Knee Surg Sports Traumatol Arthrosc 2010;18:557-69.

33 van Dijk CN, Lim LS, Bossuyt PM, et al. Physical examination is sufficient for the diagnosis of sprained ankles. J Bone Joint Surg Br 1996;78:958-62.

34 Sman $A D$, Hiller $C E$, Rae $K$, et al. Diagnostic accuracy of clinical tests for ankle syndesmosis injury. Br J Sports Med 2015;49:323-9.

35 Hawker GA, Mian S, Kendzerska T, et al. Measures of adult pain: Visual Analog Scale for Pain (VAS Pain), Numeric Rating Scale for Pain (NRS Pain), McGill Pain Questionnaire (MPQ), Short-Form McGill Pain Questionnaire (SF-MPQ), Chronic Pain Grade Scale (CPGS), Short Form-36 Bodily Pain Scale (SF-36 BPS), and Measure of Intermittent and Constant Osteoarthritis Pain (ICOAP). Arthritis Care Res 2011;63(Suppl 11):S240-52.

36 Martin RL, Burdett RG, Irrgang JJ. Development of the Foot and Ankle Disability Index (FADI). J Orthop Sports Phys Ther 1999;29:A32-A33.

37 Hopkins JT, Palmieri R. Effects of ankle joint effusion on lower leg function. Clin J Sport Med 2004;14:1-7.

38 Rohner-Spengler M, Mannion AF, Babst R. Reliability and minimal detectable change for the figure-of-eight-20 method of, measurement of ankle edema. J Orthop Sports Phys Ther 2007;37:199-205.

39 Pugia ML, Middel CJ, Seward SW, et al. Comparison of acute swelling and function in subjects with lateral ankle injury. J Orthop Sports Phys Ther 2001;31:384-8.

40 Mawdsley RH, Hoy DK, Erwin PM. Criterion-related validity of the figure-of-eight method of measuring ankle edema. J Orthop Sports Phys Ther 2000;30:149-53.

41 Tatro-Adams D, McGann SF, Carbone W. Reliability of the figure-of-eight method of ankle measurement. J Orthop Sports Phys Ther 1995;22:161-3.

42 Collins N, Teys P, Vicenzino B. The initial effects of a Mulligan's mobilization with movement technique on dorsiflexion and pain in subacute ankle sprains. Man Ther 2004; 9:77-82.

43 Hoch MC, Staton GS, McKeon PO. Dorsiflexion range of motion significantly influences dynamic balance. J Sci Med Sport 2011:14:90-2.

44 Hall EA, Docherty CL. Validity of clinical outcome measures to evaluate ankle range of motion during the weight-bearing lunge test. J Sci Med Sport 2017;20:618-21.

45 Langarika-Rocafort A, Emparanza JI, Aramendi JF, et al. Intra-rater reliability and agreement of various methods of measurement to assess dorsiflexion in the Weight Bearing Dorsiflexion Lunge Test (WBLT) among female athletes. Phys Ther Sport 2017:23:37-44.

46 Vohralik SL, Bowen AR, Burns J, et al. Reliability and validity of a smartphone app to measure joint range. Am J Phys Med Rehabil 2015;94:325-30.

47 Vicenzino B, Branjerdporn M, Teys $\mathrm{P}$, et al. Initial changes in posterior talar glide and dorsiflexion of the ankle after mobilization with movement in individuals with recurrent ankle sprain. J Orthop Sports Phys Ther 2006;36:464-71.
48 Denegar CR, Hertel J, Fonseca J. The effect of lateral ankle sprain on dorsiflexion range of motion, posterior talar glide, and joint laxity. J Orthop Sports Phys Ther 2002;32:166-73.

49 Wikstrom EA, Hubbard TJ. Talar positional fault in persons with chronic ankle instability. Arch Phys Med Rehabil 2010;91:1267-71.

50 Hubbard TJ, Hertel J. Mechanical contributions to chronic lateral ankle instability. Sports Med 2006;36:263-77.

51 Arnold BL, Linens SW, de la Motte SJ, et al. Concentric evertor strength differences and functional ankle instability: a meta-analysis. J Ath/ Train 2009;44:653-62.

52 Stark T, Walker B, Phillips JK, et al. Hand-held dynamometry correlation with the gold standard isokinetic dynamometry: a systematic review. $P m$ R 2011;3:472-9.

53 Kelln BM, McKeon PO, Gontkof LM, et al. Hand-held dynamometry: reliability of lower extremity muscle testing in healthy, physically active,young adults. J Sport Rehabil 2008; 17:160-70.

54 McCann RS, Crossett ID, Terada M, et al. Hip strength and star excursion balance test deficits of patients with chronic ankle instability. J Sci Med Sport 2017;20:992-6.

55 Arnold BL, De La Motte S, Linens S, et al. Ankle instability is associated with balance impairments: a meta-analysis. Med Sci Sports Exerc 2009;41:1048-62.

56 Docherty CL, Valovich McLeod TC, Shultz SJ. Postural control deficits in participants with functional ankle instability as measured by the balance error scoring system. Clin J Sport Med 2006;16:203-8.

57 Hiller CE, Refshauge KM, Herbert RD, et al. Balance and recovery from a perturbation are impaired in people with functional ankle instability. Clin J Sport Med 2007:17:269-75.

58 Gribble PA, Hertel J, Plisky P. Using the Star Excursion Balance Test to assess dynamic postural-control deficits and outcomes in lower extremity injury: a literature and systematic review. J Athl Train 2012;47:339-57.

59 Konradsen L, Voigt M. Inversion injury biomechanics in functional ankle instability: a cadaver study of simulated gait. Scand J Med Sci Sports 2002;12:329-36.

60 Konradsen L. Sensori-motor control of the uninjured and injured human ankle. J Electromyogr Kinesiol 2002;12:199-203.

61 Moisan G, Descarreaux M, Cantin V. Effects of chronic ankle instability on kinetics, kinematics and muscle activity during walking and running: A systematic review. Gait Posture 2017;52:381-99.

62 Hiller CE, Nightingale EJ, Lin C-WC, et al. Characteristics of people with recurrent ankle sprains: a systematic review with meta-analysis. $\mathrm{Br} J$ Sports $\mathrm{Med}$ 2011:45:660-72

63 Tegner Y, Lysholm J. Rating systems in the evaluation of knee ligament injuries. Clin Orthop Relat Res 1985:198:43-9.

64 Houston MN, Hoch JM, Hoch MC. Patient-reported outcome measures in individuals with chronic ankle instability: a systematic review. J Athl Train 2015;50:1019-33.

65 Carcia CR, Martin RL, Drouin JM. Validity of the Foot and Ankle Ability Measure in athletes with chronic ankle instability. J Ath/ Train 2008:43:179-83. 